\title{
O Uso do WhatsApp como Ferramenta de Apoio a Aprendizagem no Ensino Médio
}

\author{
Ernane Rosa Martins, IFG, Brasil, ernane.martins@ifg.edu.br \\ Luís Manuel Borges Gouveia, UFP, Portugal, lmbg@ufp.edu.pt
}

\begin{abstract}
Resumo. A educação passa por profunda mudança, devido ao uso das ferramentas tecnológicas no auxílio ao processo de ensino e aprendizagem. Assim, baseado em uma experiência de ensino com o uso do aplicativo WhatsApp, por alunos da disciplina de Autoria Web do curso técnico presencial em informática para internet. Este artigo propõe compreender as possibilidades e potencialidades da utilização do WhatsApp no Ensino Médio. Para tal, foram criados grupos do WhatsApp, nos quais acessaram e disponibilizaram conteúdos, sendo ao final aplicado um questionário eletrônico, a trinta e dois participantes, que expressaram suas percepções em relação a: Perfil, Uso da Internet e WhatsApp, Aprendizagem, Socialização, Informação e Desempenho. Os resultados mostraram que a percepção dos alunos foi positiva em relação aos elementos observados.
\end{abstract}

Palavras-chave: WhatsApp, Aprendizagem, Ensino.

\section{The Use of WhatsApp as a Tool to Support Learning in High School}

Abstract. Education undergoes profound change due to the use of technological tools to aid the teaching and learning to process. Thus, based on a teaching experience with the use of the WhatsApp application, by students of the discipline of Web Authorship of the online technical course for internet. This article proposes to understand the possibilities and potentialities of using WhatsApp in High School. To that end, WhatsApp groups were created, in which they assessed and made available content, and an electronic questionnaire was applied to thirty-two participants, who expressed their perceptions regarding Profile, Internet use and WhatsApp, Learning, Socialization, Information and Performance. The results showed that the students' perception was positive in relation to the observed elements.

Keywords: WhatsApp, Learning, Teaching.

\section{Introdução}

A tecnologia de comunicação instantânea, mediada pelos aparelhos celulares e smartphones, mudou completamente a forma das pessoas em se comunicar e relacionar, e os educadores não podem deixar de considerar esses equipamentos para serem usados no processo educacional, principalmente como integrador entre os envolvidos (Pereira; Pereira \& Alves, 2015). O uso das Novas Tecnologias Digitais de Informação e Comunicação (NTDIC) favorecem a dinamização do ensino e a produção de novos conhecimentos científicos e culturais. Sendo assim, várias iniciativas estão sendo elaboradas no sentido de promover práticas com essas ferramentas de modo a contribuir na melhoria da qualidade do ensino e do aprendizado (Borges, 2015). 
Gomez (2010, p. 88), diz que: "Os programas de redes sociais, sejam pessoais, temáticas ou profissionais, na realidade não foram criados para atividades educativas", a mesma autora afirma ainda que o uso pedagógico das redes sociais on-line e dos aplicativos para dispositivos móveis requerem certo cuidado, dizendo que: "A rede é mais um espaço da escola contemporânea que necessita orientação e cuidado para se transformar em um dispositivo pedagógico.".

A utilização de ferramentas digitas no contexto escolar simplesmente não garante a qualidade na educação, necessitando da transformação das práticas docentes. Moreira \& Kramer (2007, p. 1038), afirmam que: "Em síntese, é como se os objetos técnicos pudessem, por um passe de mágica, garantir qualidade na educação. Em muitos casos, ocorre transposição, para novos meios, dos conteúdos tradicionalmente ensinados nas salas de aula". Neste contexto, o uso e a promoção do WhatsApp como extensão da sala de aula, pode proporcionar um ambiente de aprendizagem e de colaboração. Podendo ser uma alternativa para o uso pedagógico dos dispositivos móveis sem ter que proibi-lo, podendo tornar as aulas mais atrativas e prazerosas, aumentando as possibilidades de rendimento e de aprendizado, rompendo a fronteira espacial e temporal da sala de aula (Lopes \& Vaz, 2016).

Percebe-se que nos últimos anos há uma maior facilidade de acesso às tecnologias móveis, necessitando que estas sejam inseridas nas atividades escolares de uma maneira gradativa. Sendo adaptada aos poucos por docentes, discentes e ao ambiente escolar (Alencar et al., 2015). As escolas, principalmente os professores brasileiros, são resistentes em inserir novas tecnologias nas sala de aula, por estarem envolvidos em um mundo de práticas pedagógicas tradicionais (Lima, Andrade \& Damasceno, 2010). Sendo assim, o objetivo deste trabalho é compreender as possibilidades e potencialidades da utilização do WhatsApp no Ensino Médio. Este artigo está estruturado em cinco seções. Esta seção apresenta, problemática, o objetivo, a justificativa e a estrutura da pesquisa. A seção 2 traz o referencial teórico. Na seção 3 são apresentados o método, as técnicas e procedimentos metodológicos. Na seção 4 estão descritos os resultados obtidos e discussão. Por fim, a seção 5 retoma o objetivo, como foi alcançado e sugestões de pesquisas futuras.

\section{Revisão Bibliográfica}

Nesta seção são contextualizadas as Tecnologias Móveis e o WhatsApp e as NTDIC nos processos de ensino e aprendizagem.

\subsection{Tecnologias Móveis e WhatsApp}

O WhatsApp é um aplicativo multiplataforma que utiliza a internet para envio e recebimento de mensagens instantâneas de maneira gratuita e ilimitada. $\mathrm{O}$ aplicativo possibilita o envio de diferentes mídias, tais como: imagem, áudios e vídeos. Existem outros recursos importantes, tais como: a possibilidade de criação de grupos com até 256 membros, transmitir diálogos, realizar chamadas, anexar documentos, mapas, posição do usuário, status, entre outras. Uma das principais vantagens deste aplicativo é a sua sincronização com a lista de contatos, não sendo necessário memorizar nome de usuário e senha, bastando adicionar ou ter os números salvos nos contatos do celular (Alencar et al., 2015). 
O WhatsApp é uma ferramenta utilizada por uma boa parte dos alunos, se não todos, podendo facilitar o processo de comunicação entre os alunos e professor e também entre os próprios alunos, podendo criar um cenário propício para debates sobre diversos temas das disciplinas (Paiva et al., 2016). Honorato \& Reis (2014, p. 3) afirmam que "para os alunos as vantagens do aplicativo WhatsApp são de passar informações sobre as matérias, tirar dúvidas sobre conteúdos, tarefas ou trabalhos".

Para Niza (2016), o uso do WhatsApp na escola pode facilitar o compartilhamento entre os integrantes das equipes, pois os grupos criados no aplicativo permitem que os professores troquem experiências sobre suas práticas pedagógicas e indiquem materiais didáticos e atividades, permitem também aproximar os pais da rotina escolar dos filhos, enviando recados, informando os eventos, atividades, comunicados, fotos, dicas de estudo e relatórios de desempenho escolar dos alunos, permite ainda, disponibilizar conteúdos e atividades extras para os alunos, funcionando como um Ambiente Virtual de Aprendizagem (AVA), possibilitando a disponibilização de conteúdos no formato de áudio e vídeo e a criação de fóruns de discussão e plantão de dúvidas.

Existem vários autores que pesquisaram ultimamente a utilização do WhatsApp na educação, tais como: Kaieski, Grings \& Fetter (2015), mostraram que o uso do WhatsApp promoveu um maior engajamento, participação e colaboração dos discentes no processo de ensino e aprendizagem significativa para além dos limites físicos da sala de aula; Pereira, Pereira \& Alves (2015), afirmam que o WhatsApp vai muito além de ser um simples distribuidor de conteúdo; Souza et al. (2014), dizem que o WhatsApp é uma das ferramentas mais empreendedoras do mundo, que possui como seu maior atrativo a possibilidade da troca de informações instantâneas entre usuários de todo 0 planeta através de tecnologia e inovação; Neri (2015), afirma que o WhatsApp pode ser utilizado como ferramenta multimídia para tornar as aulas mais atraentes e consequentemente melhorar a relação entre aluno e professor; Leite \& Silva (2015), apresentam uma caracterização do gênero chat por meio do aplicativo WhatsApp, dada sua relevância e popularidade entre usuários de dispositivos móveis; Machado-Spence (2014), apresenta reflexões preliminares sobre uma experiência interdisciplinar que se valeu do aplicativo WhatsApp Messenger como recurso para trocas e discussão de ideias em um trabalho sobre Bullying e Cyberbullying, e Araújo \& Bottentuit Junior (2015), apresentam o WhatsApp como aplicativo de comunicação didático-pedagógica viável ao ensino de filosofia, visto que muitos estudantes possuem celulares que acessam este aplicativo, além de atrair a atenção dos estudantes por se tratar de algo inovador, enquanto estratégia de ensino.

\subsection{As NTDIC nos processos de ensino e de aprendizagem}

Oliveira et al., (2014, p. 3484) afirmam que "o MLearning é entendido como sendo a junção dos conceitos de mobilidade e aprendizagem". Neste sentido Moran (2013) diz que a escola tem a obrigação de fazer uso da tecnologia, e tirar algum proveito. Não se pode aceitar nos dias de hoje que o professor não faça uso de recurso tecnológicos em suas aulas. Coscarelli \& Riberiro (2011, p. 91) dizem que precisa-se que reconheça a importância das tecnologias, fazendo desta uma aliada na produção do conhecimento. Moran (2013, p. 27), afirma ainda que a escola precisa ter papel inovador, inserindo a internet como um importante componente metodológico. 
Para Moran (2013, p.31) o uso das NTDIC em sala de aula podem trazer melhorias significativas para a aprendizagem, transformando a escola em um espaço rico de aprendizagem, motivando os alunos a aprender ativamente, a pesquisar o tempo todo, a serem proativos, a saberem tomar iniciativas e interagirem". É fundamental que o professor contemporâneo envolva-se com as NTDIC na sua vivência e prática pedagógica escolar, sendo que os alunos já utilizam e estão adaptados a estas novas tendências tecnológicas. Segundo Lévy (2010, p. 173), o professor não pode mais ter como função a difusão dos conhecimentos, já disponibilizados de maneira eficaz por outros meios, mas incentivar a aprendizagem e o pensamento. $\mathrm{O}$ professor agora tornouse um gestor da aprendizagem incitando à troca de saberes, realizando a mediação do processo de aprendizagem. O papel do professor, conforme Moran (2015, p. 24), é de curador e orientador, escolhendo o que é relevante entre as inúmeras informações disponíveis e orientando os alunos com os materiais e atividades disponíveis, seja em grupo ou individualmente.

Para Saccol Schlemmer \& Barbosa (2011, p. 25), o m-learning: se refere a processos de aprendizagem apoiados pelo uso de tecnologias da informação ou comunicação móveis e sem fio, cuja característica fundamental é a mobilidade dos aprendizes, que podem estar em espaços formais de educação, tais como: salas de aula, salas de formação, capacitação e treinamento, mas também em espaços informais de educação, completamente distantes uns dos outros, tais como: no local de trabalho ou em casa.

\section{Metodologia}

Nesta seção é apresentado a metodologia utilizada. A pesquisa foi aplicada em trinta e dois alunos da disciplina de autoria web do curso técnico em informática para internet. Os alunos acessaram e disponibilizam os conteúdos em um grupo do WhatsApp, o qual foi utilizado durante o primeiro semestre como ferramenta de aprendizado. Foi criado um questionário eletrônico no Google Docs e enviado aos alunos para recolher informações e compor os resultados, obtendo a participação dos trinta e dois alunos da disciplina.

O grupo criado foi utilizado como: fóruns de discussão, centrais para tirar dúvidas, no desenvolvimento de textos colaborativos e no compartilhamento de links, vídeos, sites, imagens e áudios que pudessem auxiliar e estimular o aprendizado, sobre a orientação do professor, que determinou como, quais e quando estes recursos seriam utilizados. A pesquisa em questão utilizou da abordagem qualitativa, buscando analisar e interpretar aspectos complexos do comportamento humano, tais como, atitudes e tendências de comportamento, e quantitativa, utilizando de análise dos dados brutos e linguagem matemática para descrever a relação entre as variáveis (Marconi \& Lakatos, 2010; Fonseca, 2002).

A presente pesquisa segundo Vergara (2014), é classificada quanto aos fins, como exploratória, descritiva e explicativa, e quanto aos meios de investigação como um estudo de caso, com o instrumento de observação direta das interações e as percepções dos alunos, buscando a compreensão de um fenômeno em uma situação particular, não permitindo a generalização. Optou-se por um questionário semiestruturado, pelo caráter quantitativo da pesquisa, sendo este dividido em grupos, 
com objetivos específicos, com várias afirmações com quatro opções de respostas, sendo elas: Concordo Totalmente (CT), Concordo Parcialmente (CP), Discordo Parcialmente (DP), Discordo Totalmente (DT). O questionário foi elaborado levando em conta aspectos como: Perfil (características dos respondentes), Uso da Internet e WhatsApp (hábitos de uso), Aprendizagem (impactos na compreensão dos conteúdos), Socialização (relações interpessoais), Informação (difusão e compartilhamento de informações) e Desempenho (rendimento acadêmico). A opção por um questionário online tem como virtude o fator privacidade e tempo de resposta dos participantes.

\section{Resultados e Discussões}

Através das respostas recolhidas a partir do questionário eletrônico, constatou-se que todos os alunos responderam que tem celular do tipo smartphone e utilizam o WhatsApp. Assim como Araújo \& Bottentuit Junior (2015), em suas pesquisas, atualmente praticamente todos os alunos possuem smartphone com acesso à internet. Sendo assim, é importante pensar em propostas que incluam smartphone em suas atividades com fins educacionais, visto o uso destes aparelhos atualmente. Perguntou-se aos discentes participantes da pesquisa se o WhatsApp poderia ser utilizado como ferramenta de apoio ao ensino e aprendizagem, todos os alunos responderam que sim. Mostrando que na percepção dos alunos, mesmo a ferramenta não sendo própria para o uso pedagógico, pode trazer benefícios quando utilizada nos estudos.

Pelo fato da pesquisa ocorrer em um curso de nível médio, observa-se a predominância de indivíduos jovens de 15 a 17 anos, do sexo feminino, solteiros, que estudam e não trabalham. Os respondentes utilizam a Internet por várias horas ao dia, com predominância dos dispositivos móveis, tendo a escola e a residência como pontos de acesso mais frequentes. Quando questionados sobre quais motivos os levam a usarem o WhatsApp, responderam: interações com as pessoas, compartilhamento de arquivos, conversas em geral, obtenção de informações e ligações. Sendo o principal motivo a interação com as pessoas. A Tabela 1 ilustra algumas das perguntas realizadas e suas respostas, onde foi utilizado as alternativas: Concordo Totalmente (CT), Concordo Parcialmente (CP), Discordo Parcialmente (DP), Discordo Totalmente (DT).

Tabela 1 - Algumas das perguntas realizadas e respostas dos alunos.

\begin{tabular}{|l|c|c|c|c|}
\hline \multicolumn{1}{|c|}{ Perguntas } & CT & CP & DP & DT \\
\hline $\begin{array}{l}\text { O grupo criado no WhatsApp ajudou a compreender melhor os } \\
\text { conteúdos da disciplina? }\end{array}$ & 22 & 9 & 1 & 0 \\
\hline $\begin{array}{l}\text { Os recursos como fotos e áudios foram úteis na explanação dos } \\
\text { conteúdos? }\end{array}$ & 19 & 10 & 2 & 1 \\
\hline $\begin{array}{l}\text { Consegui resolver os exercícios propostos com mais facilidade } \\
\text { pois pude aprender melhor? }\end{array}$ & 18 & 14 & 0 & 0 \\
$\begin{array}{l}\text { Conseguiu dirimir melhor as dúvidas com maior ajuda do do } \\
\text { professor? }\end{array}$ & 23 & 9 & 0 & 0 \\
\hline Fiquei satisfeito em relação à forma de se comunicar? & 13 & 17 & 1 & 1 \\
\hline Fiquei satisfeito em relação à metodologia utilizada? & 8 & 22 & 2 & 0 \\
\hline $\begin{array}{l}\text { Fiquei satisfeito em relação ao aplicativo utilizado nas } \\
\text { atividades? }\end{array}$ & 13 & 18 & 1 & 0 \\
\hline Fui mais acolhido como o grupo do WhatsApp? & 12 & 14 & 4 & 2 \\
\hline
\end{tabular}




\begin{tabular}{|l|c|c|c|c|}
\hline A matéria foi mais aprofundada com os debates no WhatsApp? & 13 & 16 & 2 & 1 \\
\hline O grupo do WhatsApp possibilitou ampliar os debates & 17 & 13 & 1 & 1 \\
\hline $\begin{array}{l}\text { O envolvimento dos colegas no grupo melhorou as relações em } \\
\text { sala de aula? }\end{array}$ & 13 & 14 & 2 & 3 \\
\hline Fiquei mais interativo e participativo com o grupo? & 15 & 14 & 2 & 1 \\
\hline As informações disponibilizadas no grupo eram úteis para mim? & 16 & 11 & 3 & 2 \\
\hline A interatividade no grupo foi maior que em sala de aula? & 15 & 10 & 5 & 2 \\
\hline Consegui as informações mais rápidas pelo grupo? & 22 & 10 & 0 & 0 \\
\hline As informações fornecidas no grupo foram corretas? prazos de entrega de & 28 & 4 & 0 & 0 \\
\hline $\begin{array}{l}\text { Fiquei informado sobre datas de provas, prán } \\
\text { exercícios, seminários. }\end{array}$ & 12 & 12 & 6 & 2 \\
\hline $\begin{array}{l}\text { O uso do WhatsApp na disciplina contribuiu para o meu } \\
\text { rendimento? }\end{array}$ & 14 & 6 & 2 \\
\hline $\begin{array}{l}\text { O grupo favoreceu a realização de trabalhos e exercícios com } \\
\text { mais qualidade? }\end{array}$ & 10 & 15 & 2 & 5 \\
\hline $\begin{array}{l}\text { Fiquei muito satisfeito em relação à forma como as atividades } \\
\text { forma propostas? }\end{array}$ & 12 & 16 & 3 & 1 \\
\hline
\end{tabular}

Analisando as respostas percebe-se que a maioria dos estudantes avaliaram de forma positiva a contribuição do WhatsApp na aprendizagem. Entre os resultados verificou-se que na opinião dos alunos, o professor ter a tecnologia a disposição para tirar as dúvidas é um fator importante e faz a diferença. Verificou-se menos timidez nas interações on-line, a maioria afirma que se sentiu mais à vontade para interagir e contribuir com o grupo. Apesar de ser verificado pelo professor que alguns assuntos debatidos eram fora do conteúdo da disciplina.

Percebe-se que um ponto extremamente positivo foi o compartilhamento de informações relevantes para a disciplina, tanto as informações disponibilizadas para estudo como informações sobre exercícios, trabalhos, seminários e provas. Quando perguntados como o uso do aplicativo contribuiu para a sua aprendizagem? A Tabela 2 ilustra como responderam alguns deles.

Tabela 2 - Contribuição com a aprendizagem dos alunos.

\begin{tabular}{|l|l|}
\hline Pergunta & \multicolumn{1}{c|}{ Respostas } \\
\hline & Através do celular foi possível interagir com a turma; \\
& $\begin{array}{l}\text { Deixou mais fácil o acesso ao conteúdo que estava sendo estudado; } \\
\text { Acho legal e criativo; }\end{array}$ \\
Como o uso do & Eu gostei, traz interação com a turma e o debate sobre o conteúdo; \\
aplicativo durante & Ai, não sei muito, mas achei legal, me entrosei mais com a matéria; \\
a atividade & Na facilidade de uso, pois já estamos familiarizados; \\
contribuiu para a & Eu consegui entender muito mais fácil o conteúdo; \\
sua & Pude discutir sobre o tema e agregar conhecimento; \\
aprendizagem? & É mais produtivo; contribui de forma dinâmica; \\
& Ajudou na interação com os demais colegas e o professor e a \\
& aumentar o interesse dos alunos; \\
& Faz com que o interesse na matéria seja maior; \\
& Contribuiu de uma boa forma. \\
\hline
\end{tabular}


Os estudantes relataram como possíveis limitações: não possuir internet e permitir que o aluno se distraia e utilize o celular para outros fins. Os alunos solicitaram que continue com a utilização do aplicativo para comunicação e compartilhamento de conteúdo na disciplina e afirmaram que iriam solicitar que outros professores também passassem a utilizar o WhatsApp nas aulas. Entre os pontos positivos destacados pelos alunos nas respostas, temos: auxilio do professor para tirar as dúvidas em tempo quase que instantâneo; possibilidade de compartilhamento de fotos, áudios e vídeos; possibilidade de resgatar conteúdos no caso de perder a aula, maior envolvimento e participação. A Tabela 3 apresenta alguns pontos positivos relatados pelos alunos com a utilização do WhatsApp.

Tabela 3 - Pontos positivos relatados pelos alunos.

\begin{tabular}{|c|c|}
\hline Pergunta & Respostas \\
\hline $\begin{array}{l}\text { Quais os } \\
\text { pontos } \\
\text { positivos com } \\
\text { a utilização do } \\
\text { WhatsApp? }\end{array}$ & $\begin{array}{l}\text { Melhorou a relação do professor com os alunos; } \\
\text { Facilitou os estudos; } \\
\text { Proporcionou mais tempo para estudar; } \\
\text { Ajudou a tirar as dúvidas; } \\
\text { Proporcionou aos alunos estudar mais e ajudar os colegas; } \\
\text { Facilitou os estudos de temas que não entendiam muito só com as } \\
\text { explicações do professor na sala; } \\
\text { Ajudou a tirar dúvidas sem ter que esperar até a próxima aula; } \\
\text { Aumentou a comunicação com o professor; } \\
\text { Permitiu estudar em qualquer lugar e ter o professor sempre por perto; } \\
\text { Proporcionou aprendizagem coletiva, colaborativa e trocas constantes } \\
\text { de conhecimento; } \\
\text { Possibilitou adiantar conteúdos e assuntos; } \\
\text { Permitiu o uso de vídeos, áudios e imagens para melhor ilustrar o } \\
\text { conteúdo a ser estudado; } \\
\text { Permitiu a criacão de grupos para socialização. }\end{array}$ \\
\hline
\end{tabular}

Foi sugerido que cada professor deveria criar um grupo para sua disciplina. Um fato importante relatado é o estreitamento de laços na relação professor e alunos, pois segundo os próprios estudantes as aulas passaram a ser "menos chatas" além dos alunos sentirem o professor mais presente e atuante dentro e fora da sala de aula.

Em relação à média das notas dos alunos comparando com a média das notas da turma do ano anterior, foi possível observar que quando não utilizou o WhatsApp, a média da turma foi 6,3, enquanto com a utilização da ferramenta em questão a média no mesmo período foi 7,9. Mas está observação não serve como comprovação de que a ferramenta WhatsApp influenciou diretamente no rendimento acadêmico da turma. Por fim, este estudo também confirmou alguns achados encontrados em outros trabalhos realizados, apontando o potencial pedagógico do WhatsApp, tais como: Rambe \& Bere (2013) interatividade, compartilhamento de conhecimento, motivação, colaboração, sincronicidade e assincronicidade; Park, Cho \& Lee (2014) sensação de presença, compartilhamento da emoção; e Padrón (2014) baixo investimento. Assim como, diversos potenciais não identificados na literatura, tais como: responsabilidade, atividade e autonomia dos alunos dentro do processo de aprendizagem. 


\section{Considerações Finais}

Este trabalho apresenta uma análise das possibilidades e potencialidades da utilização do WhatsApp no Ensino Médio. Neste sentido, observou-se que ao final das atividades os alunos sentiram-se bastante motivados e ativos dentro do processo de aprendizagem utilizando o WhatsApp, pois este permitiu compartilhar e acessar conteúdos, como e quando quiserem. Percebeu-se também que nas atividades realizadas pelos alunos, houve um grande esforço por parte dos estudantes para atingir os objetivos propostos, comprovando o aspecto motivador. Outro ponto importante foi que alguns alunos escolheram conteúdos que não foram disponibilizados pelo professor, demonstrando autonomia. Foi possível observar ainda, através da análise das respostas, o amadurecimento dos alunos, visto que muitos se questionaram se a ferramenta poderia ser um meio de distração e assim prejudicar seu aprendizado, mostrando a responsabilidade dos mesmos.

Durante as atividades foram apresentadas diversas dificuldades práticas em relação aos assuntos, sendo estes esclarecidos pelo professor ou pelos colegas, consolidando e lapidando esses conceitos de forma iterativa fora e dentro da sala de aula. Outro ponto importante foi que alguns alunos conseguiram vislumbrar, outras vertentes de pesquisas não triviais, demonstrando um aprimoramento da busca por outros conhecimentos. Os alunos se sentiram à vontade para utilizar o aplicativo com fins pedagógicos, mas ficou claro que é de extrema importância a mediação, supervisão e orientação do professor, para garantir o rendimento e não desviar dos objetivos propostos.

A realização desta pesquisa, levou professores de outras disciplinas a adotar a criação de grupos com finalidade pedagógica em diferentes turmas, e até mesmo a direção da escola passou a usar grupos para se aproximar dos alunos, expor avisos e se comunicar com os pais dos alunos na tentativa de trazê-los, mesmo que de forma virtual, para mais perto da comunidade escolar. Como trabalhos futuros, pretende-se replicar a experiência em outras turmas do ensino médio, a fim de verificar e comparar com outros resultados levantados.

\section{Referências Bibliográficas}

ALENCAR, G. A.; PESSOA, M. S.; SANTOS, A. K. F. S.; CARVALHO, S. R. R.; LIMA, H. A. B. WhatsApp como ferramenta de apoio ao ensino. In: Anais dos Workshops do Congresso Brasileiro de Informática na Educação. Sociedade Brasileira de Computação, Maceió, p. 787-795, 2015.

ARAÚJO, P. C \& BOTTENTUIT JUNIOR, J. B. O aplicativo de comunicação WhatsApp como estratégia no ensino de Filosofia, Temática (João Pessoa. Online), v. XI, p. 11-23, 2015.

BORGES, P. F. B. Novas Tecnologias Digitais da Informação e Comunicação Aplicadas ao Ensino Médio e Técnico de uma Escola da Rede Pública Federal de Uberaba - MG. 2015. 158 f. Dissertação (Mestrado em educação) - Universidade Federal do Triângulo Mineiro, Uberaba (MG), 2015. 
COSCARELLI, C. V., RIBERIRO, A. E. (ORGS.). Letramento digital: aspectos sociais e possibilidades pedagógicas. $3^{\mathrm{a}}$ ed. - Belo Horizonte: Ceale; Autêntica Editora, 2011.

FONSECA, J. J. S. Metodologia da pesquisa científica. Fortaleza: UECE, Apostila, 2002.

GOMEZ, M. V. Cibercultura, formação e atuação docente em rede: guia para professores. Brasília: Liberlivros Editora, 2010.

HONORATO, W. A. M.; REIS, R. S. F. WhatsApp - uma nova ferramenta para o ensino. In: Anais do IV Simpósio de Desenvolvimento, Tecnologias e Sociedade, p. 1-6, 2014.

KAIESKI, N.; GRINGS, J. A.; FETTER, S. A. Um estudo sobre as possibilidades pedagógicas de utilização do WhatsApp. RENOTE Revista Novas Tecnologias na Educação, v. 13, p. 1-10, 2015.

LEITE, N. C.; SILVA, M. O. WhatsApp: caracterização do gênero chat em contexto de ensino de línguas estrangeiras. Revista Texto Livre, v. 8, p. 85-97, 2015.

LÉVY, P. Cibercultura. Tradução de Carlos Irineu da Costa - São Paulo: Editora 34, 2010.

LIMA, J. O., ANDRADE, M. N. \& DAMASCENO, R. J. A. A resistência do professor diante das novas tecnologias, p. 1-4, 2010. Acesso em 24 de Maio de 2018 de <http://meuartigo.brasilescola.com/educacao/a-resistencia-professor-diantedas-novastecnologias.htm>.

LOPES, C. G.; VAZ, B. B. O Uso Pedagógico dos Grupos do WhatsApp no Ensino de História. In: V Congresso Internacional de História - Novas Epistemes e Narrativas Contemporâneas, p. 1-28, Jatai, 2016.

MACHADO SPENCE, N. C. F. O WhatsApp Messenger como Recurso no Ensino Superior: Narrativa De Uma Experiência Interdisciplinar. Revista de Educação do Vale do Arinos - RELVA, v. 1, p. 1-14, 2014.

MARCONI, M. A. LAKATOS, E. M. Metodologia do Trabalho Científico. 7. Ed. São Paulo: Atlas, 2010.

MORAN, J. M. Novas tecnologias e mediação pedagógica. 21 ed. rev. E atual. Campinas, SP: Papirus, 2013.

MORAN, J. M. Educação híbrida: Um conceito-chave para a educação hoje. In: Bacich, Lilian; Neto, Adolfo Tanzi; Trevisani, Fernando de Mello. Ensino híbrido: personalização e tecnologia na educação. Porto Alegre: Penso, 2015.

MOREIRA, A. F. B.; KRAMER, S. Contemporaneidade, Educação e Tecnologia. Educ. Soc., Campinas, vol. 28, n. 100 - Especial, p. 1037- 1057, 2007. Disponível em: <http://www.scielo.br/pdf/es/v28n100/a1928100.pdf> Acesso em: 12/04/2018.

NERI, J. H. P. Mídias Sociais em Escolas uso do WhatsApp como ferramenta pedagógica no ensino médio. Estação Científica (Juiz de Fora. Impresso), p. 1-25, 2015 . 
NIZA, C. Como usar o WhatsApp na escola. Blog Tecnologia na Educação, 2016. Disponível em: < https://novaescola.org.br/conteudo/4688/como-usar-o-whatsappna-escola>. Acesso em: 17 abr. 2018.

OLIVEIRA, E. D. S.; MEDEIROS, H.; LEITE, J. E. R.; ANJOS, E. G.; OLIVEIRA, F. S. Proposta de um modelo de cursos baseado em mobile learning: um experimento com professores e tutores no WhatsApp. In: XI ESUD Congresso Brasileiro de Ensino Superior à Distância, Florianópolis - SC. Pesquisa na EaD: reflexões sobre teoria e prática. Florianópolis - SC: NUTE UFSC. v. 1. p. 3482-3496, 2014.

PADRÓN, C. J. Estrategias Didácticas basadas en Aplicaciones de Mensajería Instantánea WHATSAPP exclusivamente para Móviles: (Mobile Learning) y el uso de la Herramienta para promover el Aprendizaje Colaborativo. Eduweb, v. 7, n. 2, p. 123-134, 2014.

PAIVA, L. F.; FERREIRA, A. C.; CORLETT, E. F. A utilização do WhatsApp como ferramenta de comunicação didático-pedagógica no ensino superior. In: Workshops do Congresso Brasileiro de Informática na Educação, p. 751-760, 2016.

PARK, S.; CHO, K.; LEE, B. G. What Makes Smartphone Users Satisfied with the Mobile Instant Messenger?: Social Presence, Flow, and Self-disclosure. International Journal of Multimedia \& Ubiquitous Engineering, v. 9, n. 11, p. 315-324, 2014.

PEREIRA, A. P.; ARAÚJO, A. R. PIBID online: uso do WhatsApp como ferramenta Didática. In V Encontro de Iniciação à Docência da Universidade Estadual da Paraíba. João Pessoa: UEPB, p. 1-9, 2015.

PEREIRA, P. C.; PEREIRA, R. S.; ALVES, J. C. Ambientes virtuais e mídias de comunicação, abordando a explosão das mídias na sociedade da informação e seu impacto na aprendizagem - o uso do WhatsApp como plataforma de m-learning. Revista Mosaico. Jan./Jun.; 06 (1), p. 29-41, 2015.

RAMBE, P.; BERE, A. Sing mobile instant messaging to leverage learner participation and transform pedagogy at a South African University of Technology. British Journal of Educational Technology. 44, 4, p. 544-561, 2013.

SACCOL, J. B. A.; SCHLEMMER, E.; BARBOSA, J. M-learning e u-learning: novas perspectivas da aprendizagem móvel e ubíqua. São Paulo: Pearson Prentice Hall, 2011.

SOUZA, A G. et al. Whatsapp, Inovação e Empreendedorismo. Rev. Expressão, p. 119, 2014.

VERGARA, S. C. Projetos e relatórios de pesquisa em administração. 15 Ed. São Paulo: Atlas, 2014. 